\title{
Reproductive rights of women with addictions
}

\section{Editorial}

Like other women, women with various addictions bear children, but not all women with addictions are able to retain custody of their children. ${ }^{1-3}$ This is because, although many such children are wanted, a substantial percentage of pregnancies in women with addictions are unplanned and inadvertent. ${ }^{4}$ Such pregnancies cause distress not only to the mother, ${ }^{5}$ but to an extended family who may not have the financial or emotional resources to help care for the children, ${ }^{6}$ and also to a larger community that may resent providing for the children. Most importantly, depending on the addiction, the children may be exposed to potentially toxic substances in utero and, thus, enter the world with a handicap. ${ }^{7-8}$ Their development further suffers if their biological mother, because of her addiction, is unable to provide them with the safety and nurturing they require. ${ }^{9,10}$

Although society at large has a responsibility to care for neglected and/ or disabled children, it remains controversial whether it has the responsibility, or the right, to prevent children-at-risk from being born. ${ }^{11}$

Access to contraception and to termination of pregnancy at the request of the mother has become possible in many jurisdictions around the world, although the prevention of birth and, especially, the termination of new life, breaches many sacred moral principles and contravenes many religious traditions. Such access is theoretically also available to women with addictions but many argue that stigma, shame, poverty, and distrust of the medical profession raise insurmountable barriers. Addiction may impair judgment and cognition, making it difficult to be consistent about contraception. Motivation is undermined by the urgency of addictive needs. Selfefficacy is damaged so that insisting on a partner's use of a condom becomes impossible. Visiting doctors for IUD insertion or long term contraceptive injections is possible for some women with addictions, but may not be for those whose relationship with their doctor has become antagonistic, or for those who are without adequate medical insurance, or for those who find it difficult to plan ahead in a realistic way. For many women, sterilization is not an option because they would like to be mothers in the future, when they are no longer addicted. In this population, abortion often seems to be the only solution when a woman becomes pregnant. ${ }^{12}$

To prevent the birth of at-risk children and to prevent abortion, some have struggled with a quasi-ethical solution- incentivizing reversible contraceptive measures that do not depend solely on the mother for their efficacy [intrauterine devices and long-term contraceptive injections]. Some have used financial incentives, paying women with cash or vouchers for adherence to long-term contraception. ${ }^{11}$ The ethics of financial incentives have been questioned because they awaken memories of the eugenics movement- government paying 'undesirables' to not procreate. Because even a relatively modest amount of money may unduly influence decision-making in an impoverished population, such incentives are seen as potentially coercive, taking away a woman's autonomy in making her decision.

Incentives, however, need not be financial. The best ones consist of contraceptive education, motivation enhancement strategies, provision of free contraceptive measures at easily accessible locations, and psychological counseling.
Volume I Issue I - 2015

Mary V Seeman

Department of Psychiatry, University of Toronto, Canada

Correspondence: Mary V Seeman, Professor Emerita, Department of Psychiatry, University of Toronto, Toronto, Ontario, Canada, Email mary.seeman@utoronto.ca

Received: April 17,2015 | Published: May 06, 2015

For women with addiction problems, the contemporary literature recommends:

a. The reduction of barriers to preconception care, contraception, and post conception information and to pregnancy termination for women with addictions. This includes the free provision of contraceptive measures on-site at drug treatment facilities and easy access to liaison with other needed services.

b. The free provision of individual, marital, parenting and family psychological counseling. ${ }^{13,14}$

c. Non-discriminatory, culture-sensitive provision of care based on the assumption that there is no 'conflict' between what is best for the woman and for her child-to-be, that all women want healthy babies and all babies need healthy mothers.

\section{Acknowledgements}

None.

\section{Conflict of interest}

The author declares no conflict of interest.

\section{References}

1. Grant T, Huggins J, Graham JC, et al. Maternal substance abuse and disrupted parenting: distinguishing mothers who keep their children from those who do not. Children and Youth Services Review. 2011;33(11):2176-2185.

2. Taplin S, Mattick RP. Mothers in methadone treatment and their involvement with the child protection system: a replication and extension study. Child Abuse Negl. 2013;37(8):500-510.

3. Taplin S, Mattick RP. The nature and extent of child protection involvement among heroin-using mothers in treatment: High rates of reports, removals at birth and children in care. Drug Alcohol Rev. 2014;34(1):31-37.

4. Black KI, Stephens C, Haber PS, et al. Unplanned pregnancy and contraceptive use in women attending drug treatment services. Aust NZ J Obstet Gynaecol. 2012;52(2):146-150.

5. Silva SA, Pires AP, Guerreiro C, et al. Balancing motherhood and drug addiction: The transition to parenthood of addicted mothers. $J$ Health Psychol. 2013;18(3):359-367.

6. Orford J, Velleman R, Natera G, et al. Addiction in the family is a major but neglected contributor to the global burden of adult ill-health. Soc Sci Med. 2013;78:70-77. 
7. Behnke M, Smith VC. Committee on Substance Abuse, Committee on Fetus and Newborn Prenatal substance abuse: short-and long-term effects on the exposed fetus. Pediatrics. 2013;131(3):e1009-e1024.

8. Narkowicz S, Plotka J, Polkowska Z, et al. Prenatal exposure to substance of abuse: a worldwide problem. Environ Int. 2013;54:141-163.

9. Barnard M, McKeganey N. The impact of parental problem drug use on children: what is the problem and what can be done to help? Addiction 2004;99(5):552-559.

10. Raitasalo K, Holmila M, Autti-Ramo I, et al. Hospitalisations and out-ofhome placements of children of substance-abusing mothers: A registerbased cohort study. Drug Alcohol Rev. 2015;34(1):38-45.
11. Lucke JC, Hall WD. Under what conditions is it ethical to offer incentives toencourage drug-using women touse long-acting forms of contraception? Addiction. 2012;107(6):1036-1041.

12. Drescher-Burke K. Contraceptive risk-taking among substance-using women. Qualitative Social Work. 2013;13(5):636-653.

13. Fowler C, Rossiter C, Sherwood J, et al. New understandings of mothering: Mothers in an abstinence-based drug treatment program. International Journal of Mental Health and Addiction. 2014;2:173-184.

14. Lund IO, Brendryen H, Ravndal E. A longitudinal study on substance use and related problems in women in opioid maintenance treatment from pregnancy to four years after giving birth. Subst Abuse. 2014;8:35-40. 